\title{
Visualizing Collaboration Characteristics and Topic Burst on International Mobile Health Research: Bibliometric Analysis
}

Lining Shen ${ }^{1,2,3}$, PhD; Bing Xiong ${ }^{1}$, MS; Wei Li ${ }^{1}$, MS; Fuqiang Lan $^{1}$, MS; Richard Evans ${ }^{4}$, PhD; Wei Zhang ${ }^{1,2}$, PhD

\author{
${ }^{1}$ School of Medicine and Health Management, Tongji Medical College, Huazhong University of Science \& Technology, Wuhan, China \\ ${ }^{2}$ Institute of Smart Health, Huazhong University of Science \& Technology, Wuhan, China \\ ${ }^{3}$ Hubei Provincial Research Center for Health Technology Assessment, Wuhan, China \\ ${ }^{4}$ Department of Business Information Management and Operations, University of Westminster, London, United Kingdom
}

\section{Corresponding Author:}

Lining Shen, PhD

School of Medicine and Health Management, Tongji Medical College

Huazhong University of Science \& Technology

No.13 Hangkong Road

Wuhan, 430030

China

Phone: 8602783692730

Fax: 8602783692727

Email: shenln@163.com

\begin{abstract}
Background: In the last few decades, mobile technologies have been widely adopted in the field of health care services to improve the accessibility to and the quality of health services received. Mobile health (mHealth) has emerged as a field of research with increasing attention being paid to it by scientific researchers and a rapid increase in related literature being reported.

Objective: The purpose of this study was to analyze the current state of research, including publication outputs, in the field of mHealth to uncover in-depth collaboration characteristics and topic burst of international mHealth research.

Methods: The authors collected literature that has been published in the last 20 years and indexed by Thomson Reuters Web of Science Core Collection (WoSCC). Various statistical techniques and bibliometric measures were employed, including publication growth analysis; journal distribution; and collaboration network analysis at the author, institution, and country collaboration level. The temporal visualization map of burst terms was drawn, and the co-occurrence matrix of these burst terms was analyzed by hierarchical cluster analysis and social network analysis.

Results: A total of 2704 bibliographic records on mHealth were collected. The earliest paper centered on mHealth was published in 1997, with the number of papers rising continuously since then. A total of $21.28 \%(2318 / 10,895)$ of authors publishing mHealth research were first author, whereas only $1.29 \%(141 / 10,895)$ of authors had published one paper. The total degree of author collaboration was $4.42(11,958 / 2704)$ and there are 266 core authors who have collectively published $53.07 \%(1435 / 2704)$ of the total number of publications, which means that the core group of authors has fundamentally been formed based on the Law of Price. The University of Michigan published the highest number of mHealth-related publications, but less collaboration among institutions exits. The United States is the most productive country in the field and plays a leading role in collaborative research on mHealth. There are 5543 different identified keywords in the cleaned records. The temporal bar graph clearly presents overall topic evolutionary process over time. There are 12 important research directions identified, which are in the imbalanced development. Moreover, the density of the network was 0.007 , a relatively low level. These 12 topics can be categorized into 4 areas: (1) patient engagement and patient intervention, (2) health monitoring and self-care, (3) mobile device and mobile computing, and (4) security and privacy.
\end{abstract}

Conclusions: The collaboration of core authors on mHealth research is not tight and stable. Furthermore, collaboration between institutions mainly occurs in the United States, although country collaboration is seen as relatively scarce. The focus of research topics on mHealth is decentralized. Our study might provide a potential guide for future research in mHealth.

(JMIR Mhealth Uhealth 2018;6(6):e135) doi: 10.2196/mhealth.9581 


\section{KEYWORDS}

collaboration characteristics; topic bursts; international mobile health; mHealth; telemedicine; bibliometric analysis; bibliometrics; research trends

\section{Introduction}

\section{Background}

With continued economic and societal development worldwide, the traditional system of health care delivery has increasingly failed to satisfy human demand in providing efficient health care services. It should be noted that numerous constraints and barriers exist to providing high-quality, accessible, and timely health services, especially in low-resource settings [1-3]. In this context, mobile technologies have been introduced into health care service delivery, and, subsequently, mobile health (mHealth) has emerged, changing the situation by offering support via mobile communication technologies [4].

mHealth is an umbrella term that encompasses areas of networking, mobile computing, medical sensors, and other communication technologies within health care [5]. The first occurrence of the term "mHealth" in literature was in the special issue entitled "Unwired e-med" on wireless telemedicine systems, published in 2000 [6]. The World Health Organization Global Observatory for eHealth defines mHealth as "Medical and public health practice supported by mobile devices, such as mobile phones, patient monitoring devices, personal digital assistants (PDAs), and other wireless devices. mHealth involves the use and capitalization on a mobile phone's core utility of voice and short messaging service (SMS) as well as more complex functionalities" [7]. Obviously, mHealth technologies can facilitate more accessible and affordable health care to all; it has presented unprecedented advantages over the past years [8]. Subsequently, it has attracted great attention from scholars, experiencing rapid development in recent years, and has become a hot topic in the health care field.

Given the importance of mHealth, some scientific researchers have focused on reviewing related literature to identify the characteristics and status of mHealth research in recent years. However, much of this effort has only considered specific subfields of mHealth, with conclusions being drawn from descriptive analysis and systematic reviews. For example, some reviews have focused on mobile health apps $[9,10]$ related to the most prevalent conditions (eg, headache disorders [11], heart failure [12], HIV/AIDS [13]), and short message service (SMS) text messaging for health improvement [14-16]. Other reviews have concentrated on the analysis of mobile health technologies [17] and mobile devices for assessment of physical activity [18]. In addition, some scholars have summarized lessons learnt from mHealth trials and studies using peer-reviewed journals, websites, and key reports [19]. However, a review of previous related literature shows some research limitations. There have been few papers that have focused on the bibliometric perspective of mHealth research, which refers to methods of analyzing the data of scientific literature quantitatively, to gain knowledge of the meta-information related to the research in question [20,21]; the combined use of methodologies that give information on different aspects of scientific output is generally recommended [22]. In addition, discussion relating to the collaborative status and overall topic burst still remains relatively scarce.

\section{Objectives}

The aim of this study, therefore, was to address these limitations by conducting a comprehensive exploration and analysis into the worldwide mHealth field, using quantitative analysis. Through this approach, major problems can be identified and raised. That is, what are the external characteristics of mHealth research, such as the growth in published literature and journal distribution? What is the status of collaboration between scholars in the field and trends in international mHealth research at the author, institution, and country level? What is the evolutionary process of the term bursts based on the high-frequency and highly bursting keywords set? What are the research topic bursts? The answers to these questions will not only supplement the previous research work completed but also contribute to further research on international mHealth.

\section{Methods}

\section{Data Collection}

In this study, we identified publications that are indexed in the Thomson Reuters Web of Science Core Collection (WoSCC) database, namely, the Science Citation Index Expanded, the Social Sciences Citation Index, and the Emerging Sources Citation Index. As WoSCC comprised most high-quality literature, and being updated continuously and dynamically, it has been identified as being most appropriate for the bibliometric analysis in this study [23].

To retrieve mHealth-related publications, as fully as possible, we formulated the following search strategy, on the basis of the above definition and reviews on mHealth (for further details on the search strategy employed, see Multimedia Appendix 1): \#1 mobile health, \#2 mHealth apps, \#3 TS=(("mobile technolog*" OR "mobile device*") AND "health*"), \#4 TI=(("mobile phone*" OR "tablet comput*" OR "personal digital assistant*") AND "health*"), \#5 TI=("mobile unit*" OR TI="mobile health unit*”), \#6 (\#1 OR \#2 OR \#3 OR \#4) NOT \#5. Moreover, "document type" was limited to paper. The time span of publication was confined from 1985 to 2016.

On the basis of the above search strategy and restrictions, a total of 2902 bibliographic records were identified and downloaded on December 28, 2016. To perfect the research, the main inclusion and exclusion criteria were formulated after 2 researchers independently reviewed and evaluated the 500 pilot bibliographic records. The inclusion criteria were as follows: (1) the contents of the papers primarily concentrated on mobile health, and (2) all study designs. The exclusion criteria were as follows: (1) the record related to book review and notifications, instead of being a regular paper; (2) the content of the research focused on animal mobile health (eg, cattle [24]), rather than being focused on human-oriented mobile health; and (3) the 
study mainly concentrated on mobile units (eg, mobile health facilities [25]), rather than integration of Information and Communication Technologies (ICT) with health care services. In this process, the titles, abstracts, and keywords of the publications in these records were screened with reference to the research objective. Any discrepancies or disagreements were discussed until consensus was reached. Then, 1 researcher screened the remaining records using the above selection criteria. Finally, a total of 198 irrelevant records were manually removed. In total, 2704 bibliographic records published from 1997 through 2016 were obtained for subsequent bibliometric analysis, so as to cast light on collaboration characteristics and research topic burst in the field of international mHealth. The entire selection process of bibliographic records on mHealth research is shown in Figure 1.

\section{Design of Data Analysis Method}

Similar to other bibliometric studies [26], a variety of analytic indicators have been employed in this research. Generally, bibliometric analysis can be used to depict and predict research trends and the direction of a given topic in a given field [27]. In this study, we analyzed literature distribution, including the growth in mHealth literature and journal distribution, using Bibliographic Item Co-occurrence Mining System (BICOMS) [28] and MS Excel 2010. In addition, core journals were identified, which normally refers to the most important journals with higher citation counts. That is, these core journals publish papers more frequently at a high academic level, which reflect the latest research findings, frontier research status, and developing trends of the subject; they are typically paid more attention by scientific researchers in the same research field.
In this research, the total number of published papers is regarded as an index of quantity of research productivity, whereas citation frequency is considered as an index of quality of research productivity. Therefore, the total local citation score (TLCS) and the total global citation score (TGCS) were calculated in this study. TLCS refers to the number of times that a set of papers included in a collection has been cited by other papers within the same collection, whereas TGCS refers to the number of times that a set of papers included in a collection has been cited in the WoSCC [29]. The average global citation score (AGCS) is the mean value of TGCS, which also indicates the average number of citations that papers in the mHealth field receive. Similarly, the average local citation score (ALCS) is the mean value of TLCS, which indicates the average number of citations that papers within the collection receive. In general, TLCS and TGCS have been the key indicators capable of evaluating the relevance of each research paper in our sample [30]. It is obvious that TLCS and TGCS can help us identify the most significant work on the topic. However, it should be noted that TLCS presents the important papers for a chosen research area, whereas TGCS mainly displays the effects of the papers related to a chosen research area on the papers in the WoSCC.

On the basis of the above indicators, HistCite, an analytical and visualization tool [31], was employed to analyze the research productivity of authors, institutions, and countries. Generally speaking, country collaboration, institution collaboration, and author collaboration are 3 primary forms of scientific collaboration. Coauthorship is fundamental in country collaboration and institution collaboration [32].

Figure 1. Selection process for obtaining bibliographic records on mHealth research.

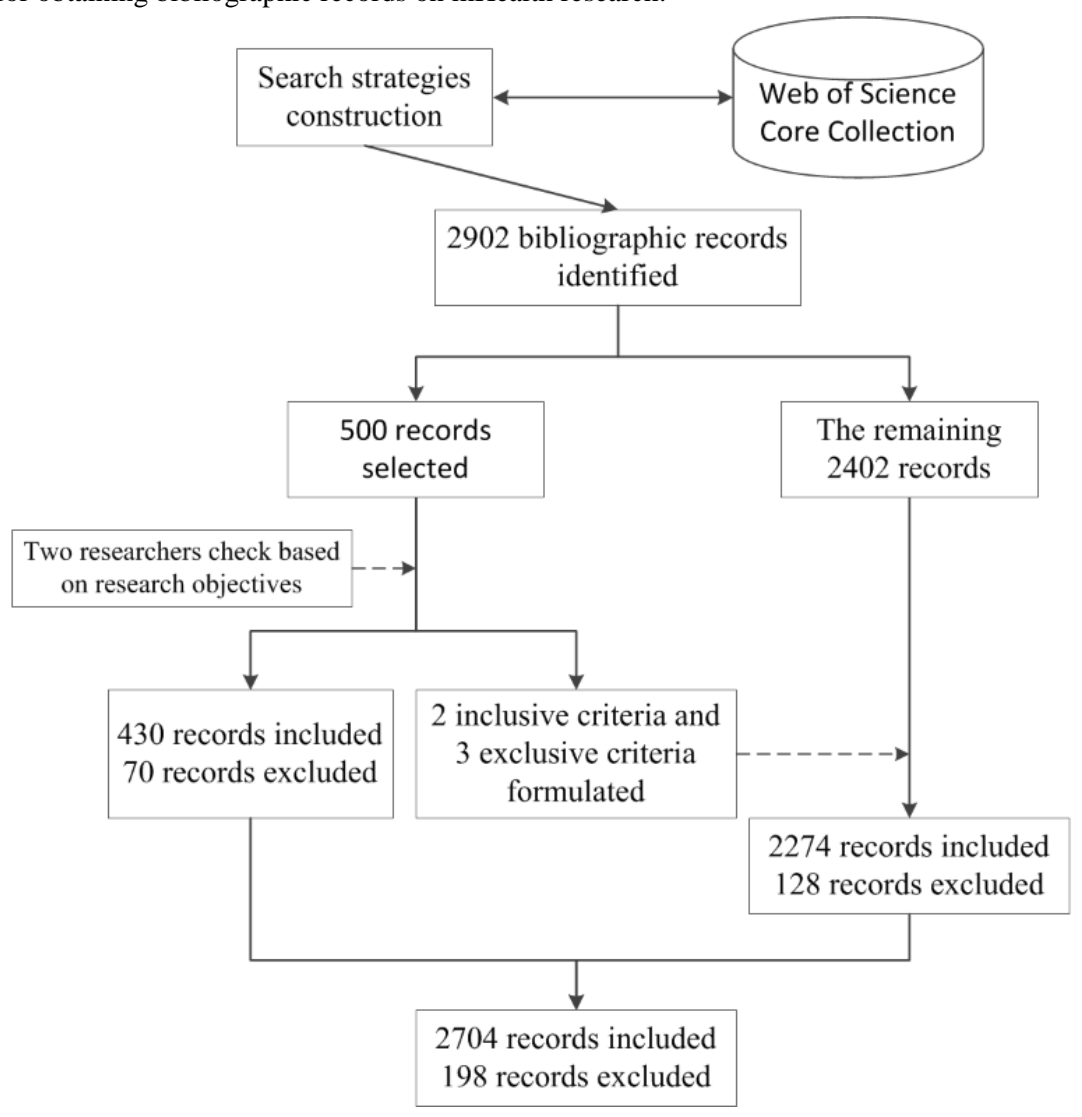


The rate of collaborative papers published is defined as the proportion of collaborated papers to the total number of papers, whereas the degree of author collaboration refers to the average number of authors per paper during a certain period of time; both indicators reflect the trend in collaborative research, to some extent [33].

CiteSpace II [34] was used to directly visualize the 3 collaboration relationships. Visual maps generated by CiteSpace are composed of nodes and links. The node displays in a purple circle; nodes normally represent the author, institution, country, and so on, whereas links represent cocitation or co-occurrence between these nodes. On the basis of Chen's definition [35], the higher citation and centrality the node has, the larger impact the node has in the cocitation map. By studying these clusters and the relationships between them, valuable information can be drawn. Finally, 4 stages were completed, as follows, regarding the analysis of research hotspots.

First, we calculated the frequencies of each keyword and created a coword matrix using BICOMS. When we considered equivalent relations between keywords, a total of 5543 keywords were identified from the publications and subsequently merged to obtain more precise results based on the following 3 principles: (1) merging of some keywords, which are entry terms, into corresponding Medical Subject Headings terms using PubMed (eg, "mobile phone," "cellular phones," and "cellular telephone" were merged into "cell phones"); (2) replacement of the full keyword into its acronym (eg, "Personal Digital Assistant" was replaced with "PDA"); and (3) merging of singular and plural keywords (eg, "mobile technology" and "mobile communication" were changed to "mobile technologies" and "mobile communications," respectively). Then, 139 keywords, with the frequency not less than 10, were chosen to generate a $139 \times 139$ co-occurrence matrix. It should be noted that the data in diagonal cells were treated as missing data, and the values of nondiagonal cells were the co-occurrence frequency [36].

Second, burst detection was conducted on the cleaned bibliographic records, and a temporal bar graph for keywords was drawn. Kleinberg's burst detection algorithm [37], which can identify sudden increases or "bursts" in the frequency of words used over time, is effective in detecting bursts in keyword popularity. We employed Science of Science (Sci2) [38], which can implement such algorithm, to detect the burst terms in the cleaned bibliographic records and calculate the burst strength which depicts the intensity of the burst, that is, how great the change is in the word frequency that triggered the burst. In total, 228 keywords with a burst strength not less than 1 were generated. However, these keywords only represented the possibility to be core keywords and needed to be further selected, according to the keyword frequency that reflects the degree of concern to some extent. The higher the number of keyword frequency, the more likely it is to become a hot topic in future. We further computed the intersection of the high-frequency (frequency $\geq 10$ ) keywords set and highly bursting (burst strength $\geq 1$ ) keywords set [39], so as to reduce the interference caused by low frequency keywords. As a result, 71 keywords were obtained. Next, a temporal visualization map for the 27 keywords with a frequency not less than 10 and burst strength not less than 2 was drawn using Sci2. Each row record is represented as a horizontal bar with a specific start and end date, with a corresponding keyword label on its left side in the temporal bar graph visualization. The area of each bar encodes a numerical value of burst strength.

Third, hierarchical cluster analysis was conducted, based on the $71 \times 71$ co-occurrence matrix. At first, we removed any rows or columns that did not correspond to any 1 of the 71 keywords from the $139 \times 139$ co-occurrence matrix. Finally, the $71 \times 71$ co-occurrence matrix was formed and then transformed into Pearson's correlation matrix, using IBM SPSS Statistics 19. In this matrix, every value in the cell indicates the similarity of each keyword pair [40]. Considering the discrete matrix data, a dissimilarity matrix was created. Subsequently, hierarchical cluster analysis was performed using SPSS 19.0 [41], and the results display directly the keywords cluster.

Finally, the visualization map and its network characters were obtained by analyzing the original Pearson's correlation matrix, using MS Excel 2010 and Ucinet6.6 [42,43]. The density of the network was calculated, with a social network map being drawn, using Ucinet6.6 and Netdraw (embodied in the Ucinet tool), to verify the result above. Furthermore, the relative size of nodes is proportional to the frequency of keywords, whereas the relative thickness of lines is drawn proportionally to the correlation between keywords [44].

\section{Results}

\section{Literature Distribution}

\section{Growth of Literature}

On the basis of the above search strategy and the cleaned data obtained, we found that the earliest paper on mHealth, indexed by WoSCC, was published in 1997 . The publication output of mHealth-related research, from 1997 to 2016, is presented in Figure 2, indicating that the number of papers concerning mHealth research has risen yearly and produced from 2 in 1997 to 765 in 2016. In terms of publication language, most (98.08\%, 2652/2704) are written in English, followed by German, Portuguese, and Spanish. Since the beginning of 2012, it should be recorded that the number of mHealth-related publications has increased considerably.

The cumulative annual number of publications has continually grown from 2 to 2704 (shown in Figure 3). A literature logical growth curve was obtained by a direct fit to the equation: $y=3913.14 /\left(1+1929.18 \mathrm{e}^{-0.39 t}\right),\left(R^{2}>0.987\right)$, where $y$ is the cumulative annual number of papers and $t$ is the number of years since 1997 . The time of the inflection point of the growth curve is: $t=\ln (1929.18) / 0.39=19.4 \approx 20(\mathrm{ie}, 2016-1997+1)$. 
Figure 2. Number of publications related to mHealth in Web of Science Core Collection (1997-2016).

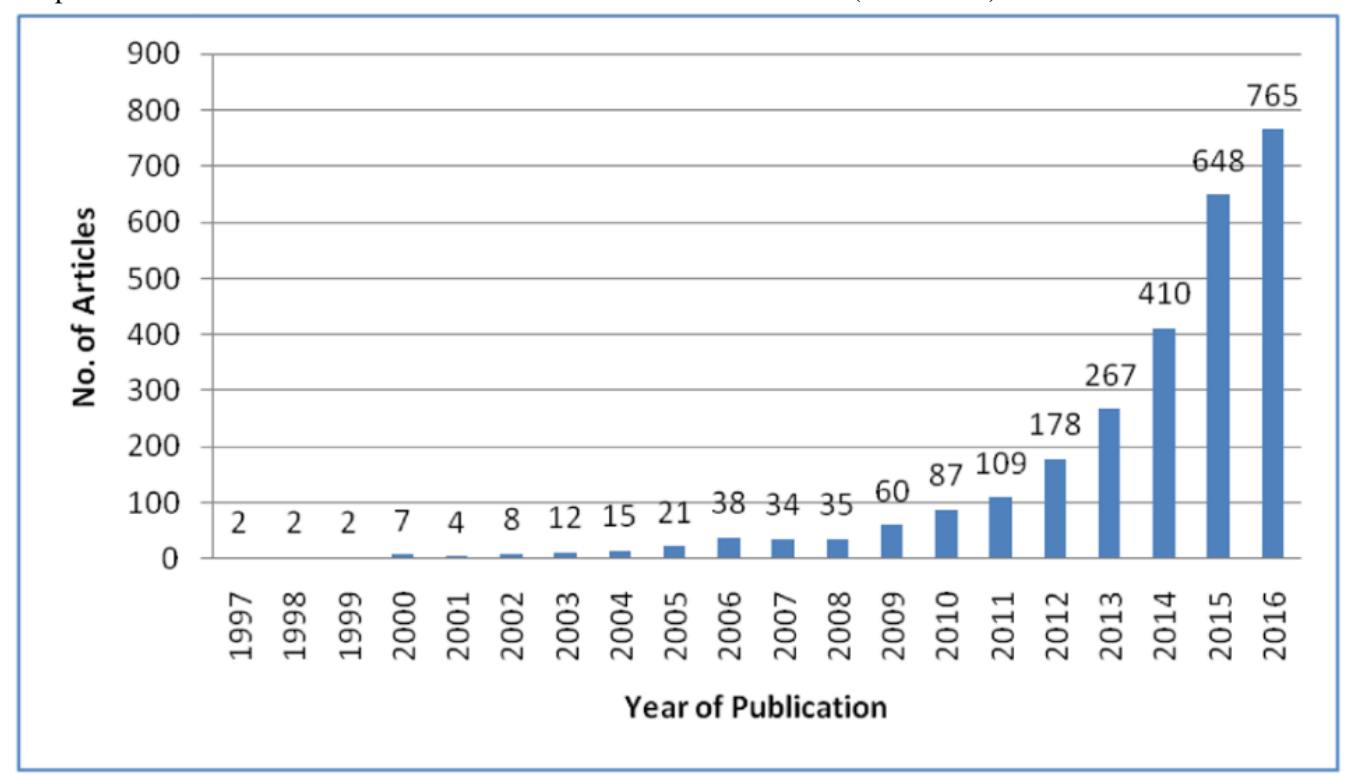

Figure 3. The relationship between cumulative number of publications and years since 1997.

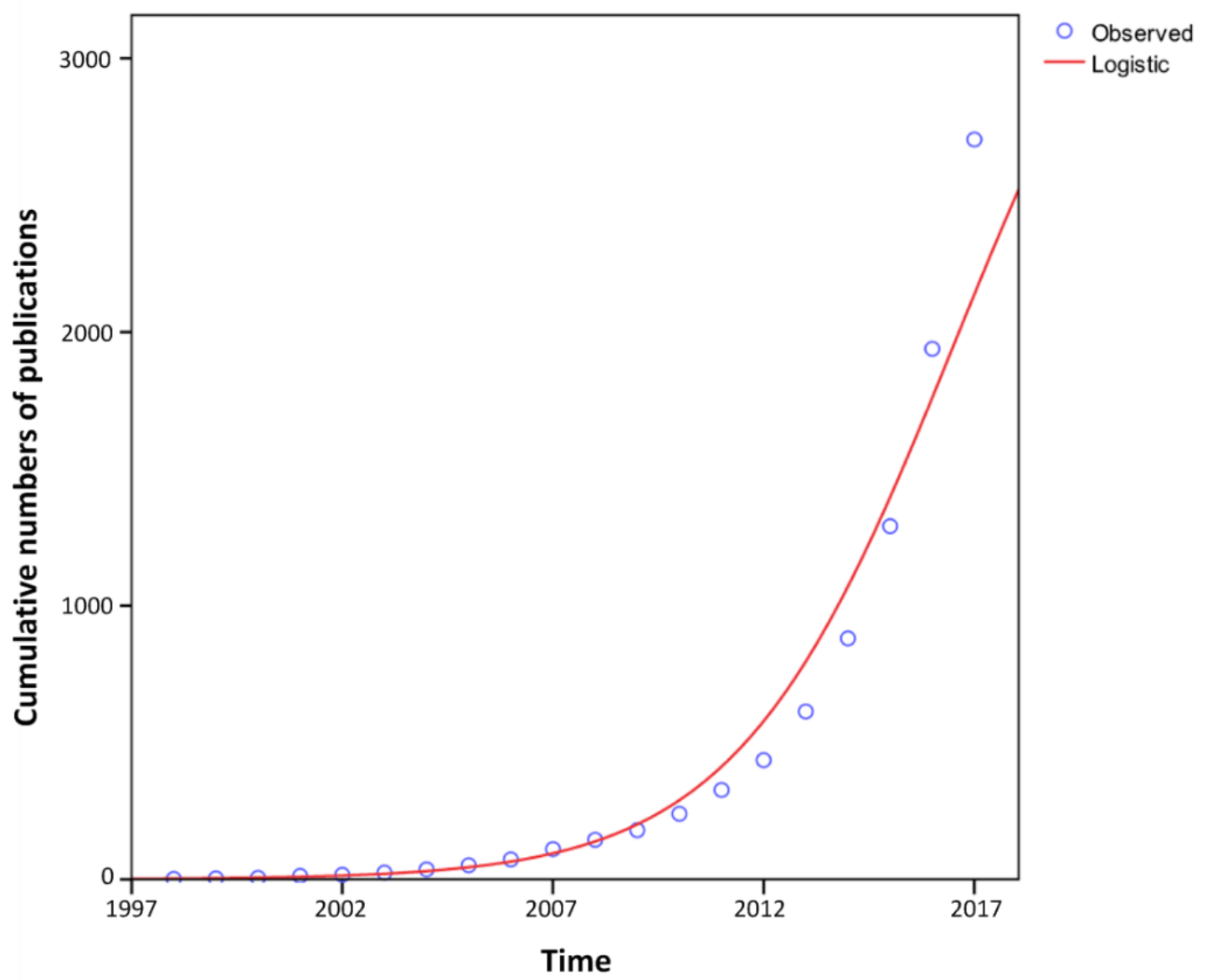

\section{Journal Distribution}

From 1997 to 2016, research relating to mHealth has been published in 1008 journals. These journals were listed in a descending order by the productivity of publication and then divided into a nucleus of journals and 2 following groups, containing approximately the same number of publications as the nucleus. Note, the "Journal of Medical Internet Research" is the most productive journal, publishing a total of 125 papers on mHealth research.

As shown in Table 1, the nucleus, covering the Top 18 journals $(1.79 \%, 18 / 1008)$, has 853 papers, accounting for $31.55 \%$ of all 2704 papers. The relationship among the number of journals in the nucleus and the 2 succeeding zones is approximately $1: 7: 7^{2}$; this follows Bradford's Law of scattering [45]. 
Table 1. Top 18 journals (by article count) on the topic of mobile health (mHealth).

\begin{tabular}{|c|c|c|c|c|c|}
\hline No. & Top journals & $\mathrm{IF}^{\mathrm{a}}(2015)$ & IF (2016) & Articles, n (\%) & Cumulative percentage \\
\hline 1 & Journal of Medical Internet Research & 4.532 & 5.175 & $125(4.62)$ & 4.62 \\
\hline 2 & Telemedicine and E-Health & 1.791 & 2.031 & $120(4.44)$ & 9.06 \\
\hline 3 & JMIR mHealth and uHealth & $\mathrm{N} / \mathrm{A}^{\mathrm{a}}$ & 4.636 & $107(3.96)$ & 13.02 \\
\hline 4 & Journal of Medical Systems & 2.213 & 2.456 & $71(2.63)$ & 15.64 \\
\hline 5 & PLoS ONE & 3.057 & 2.806 & $49(1.81)$ & 17.46 \\
\hline 6 & BMC Medical Informatics and Decision Making & 2.042 & 1.643 & $38(1.41)$ & 18.86 \\
\hline 7 & International Journal of Medical Informatics & 2.363 & 3.210 & $38(1.41)$ & 20.27 \\
\hline 8 & Journal of the American Medical Informatics Association & 3.428 & 3.698 & $37(1.37)$ & 21.63 \\
\hline 9 & BMC Public Health & 2.209 & 2.265 & $36(1.33)$ & 22.97 \\
\hline 10 & Journal of Telemedicine and Telecare & 1.377 & 2.008 & $34(1.26)$ & 24.22 \\
\hline 11 & JMIR Research Protocols & $\mathrm{N} / \mathrm{A}^{\mathrm{b}}$ & N/A & $32(1.18)$ & 25.41 \\
\hline 12 & IEEE Transactions on Information Technology in Biomedicine & N/A & N/A & $32(1.18)$ & 26.59 \\
\hline 13 & IEEE Journal of Biomedical and Health Informatics & 2.093 & 3.451 & $28(1.04)$ & 27.63 \\
\hline 14 & Journal of Health Communication & 2.013 & 1.614 & $24(0.89)$ & 28.51 \\
\hline 15 & Trials & 1.859 & 1.969 & $24(0.89)$ & 29.40 \\
\hline 16 & Health Informatics Journal & 1.578 & 3.021 & $21(0.78)$ & 30.18 \\
\hline 17 & Sensors & 2.033 & 2.677 & $19(0.70)$ & 30.88 \\
\hline 18 & Personal and Ubiquitous Computing & 1.498 & 2.395 & $18(0.67)$ & 31.55 \\
\hline
\end{tabular}

aF: impact factor.

${ }^{\mathrm{b}} \mathrm{N} / \mathrm{A}$ : not applicable.

The journal impact factor (IF), in a given year, is defined as the number of citations received by papers published in the previous 2 years, divided by the number of papers published in the same time. Table 1 shows that the journal IF rose in 2016 for 13 of the 18 top journals, when compared with 2015, except for 4 journals, namely, PLoS ONE, BMC Medical Informatics and Decision Making, Journal of Health Communication, IEEE Transactions on Information Technology in Biomedicine, and JMIR Research Protocols. Moreover, the average IF of the top 16 journals in 2016 reached 2.82. A total of 9 of the 18 journals are in the category of Medical Informatics in the Journal Citation Reports 2016.

\section{Collaboration Characteristics}

\section{Core Author and Author Collaboration}

The total number of authors who have published research in the field of mHealth is $10,895,21.27 \%(2318 / 10,895)$ of which have been as first author. However, 141 authors have published just 1 paper, comprising $1.29 \%(141 / 10,895)$ of the total. The top 7 most productive first authors with not less than 5 outputs were identified in the area of mHealth (shown in Table 2), which together contributed to the publication of 45 papers (for list of papers published, see Multimedia Appendix 2), that is, an average of 6.4 papers per first author during the period of

1997-2016. Table 2 also shows that the most productive first author in the field of mHealth is John D Piette with 11 papers, followed by Dror Ben-Zeev and David D Luxton.

In this study, a total of 2563 coauthored papers were identified, indicating that the rate of collaborative papers is $94.79 \%$ (ie, $2563 / 2704$ ). The total publication frequency of authors, which refers to the cumulative result of the number of authors of each paper, is 11,958, indicating that the degree of author collaboration was $4.42(11,958 / 2704)$ during the period of 1997 to 2016 .

The visualization network of author collaboration was created using CiteSpace based on the g-index selection criteria in each slice (shown in Figure 4). Note that several authors tended to collaborate with a small group of collaborators, generating 4 major clusters with some highly active authors. Namely, Cluster 1, takes the top spot, which includes 5 core members, including Piette JD, Allman-Farinelli M, Bauman A, Aikens JE, and Chen $\mathrm{J}$; Cluster 2 consists of Whittaker R, Maddison R, and Jiang YN; Cluster 3 contains Aschbrenner KA, Naslund JA, and Bartels SJ; and the core members of cluster 4 are Wang W, Wu Q, Chen L, and Li Y. Additionally, there are a large number of relatively smaller clusters in the collaborative map of authors (for list of relevant information for main authors of the 4 clusters, see Multimedia Appendix 3). 
Table 2. The top 7 most productive first authors during the period 1997-2016.

\begin{tabular}{|c|c|c|c|c|c|}
\hline Author name (full name) & $\mathrm{ORCID}^{\mathrm{a}}$ & Recs-first $^{\mathrm{b}}\left(\right.$ Recs-all $\left.^{\mathrm{c}}\right)$ & Percentage $^{\mathrm{d}}$ & Main affiliation & Country \\
\hline Piette JD (John D Piette) & $\mathrm{N} / \mathrm{A}^{\mathrm{e}}$ & $11(20)$ & 0.41 & $\begin{array}{l}\text { Ann Arbor Department of } \\
\text { VA, Center for Clinical } \\
\text { Management Research, } \\
\text { Michigan }\end{array}$ & United States \\
\hline Ben-Zeev D (Dror Ben-Zeev) & 0000-0001-6597-2407 & $8(10)$ & 0.30 & $\begin{array}{l}\text { Dartmouth Medical School, } \\
\text { Hanover }\end{array}$ & United States \\
\hline Luxton DD (David D Luxton) & N/A & $6(6)$ & 0.22 & $\begin{array}{l}\text { The National Center for } \\
\text { Telehealth and Technology, } \\
\text { Tacoma, Washington }\end{array}$ & United States \\
\hline Chib A (Arul Chib) & N/A & $5(5)$ & 0.18 & $\begin{array}{l}\text { Nanyang Technological } \\
\text { University }\end{array}$ & Singapore \\
\hline $\begin{array}{l}\text { Turner-McGrievy, GM } \\
\text { (Gabrielle M Turner-McGrievy) }\end{array}$ & 0000-0002-1683-5729 & $5(7)$ & 0.18 & $\begin{array}{l}\text { University of South Caroli- } \\
\text { na, Columbia, South Caroli- } \\
\text { na }\end{array}$ & United States \\
\hline $\begin{array}{l}\text { Aschbrenner KA (Kelly A As- } \\
\text { chbrenner) }\end{array}$ & N/A & $5(9)$ & 0.18 & $\begin{array}{l}\text { Geisel School of Medicine } \\
\text { at Dartmouth, Lebanon, NH }\end{array}$ & United States \\
\hline Akter S (Shahriar Akter) & 0000-0002-2050-9985 & $5(5)$ & 0.18 & University of Wollongong & Australia \\
\hline
\end{tabular}

${ }^{\mathrm{a} O R C I D:}$ Open Researcher and Contributor ID.

${ }^{b}$ Recs-first: number of papers published as first author.

${ }^{\mathrm{c}}$ Recs-all: total number of papers published by the author.

${ }^{\mathrm{d}}$ Percentage: Percentage of papers published as first author.

${ }^{\mathrm{e}} \mathrm{N} / \mathrm{A}$ : not applicable.

Figure 4. The collaboration relationship of productive authors publishing mHealth research.

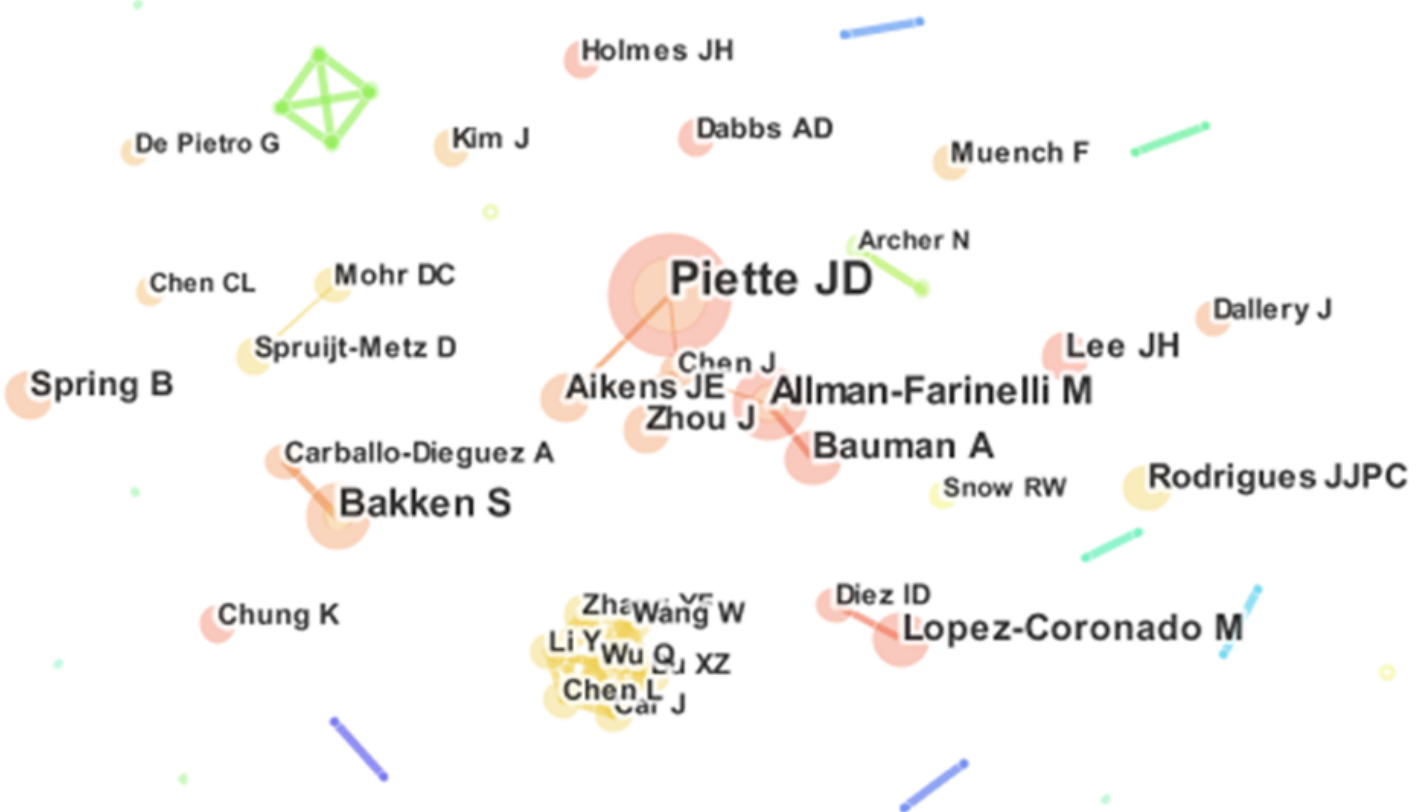

\section{Aschbrenner KA} Nas'inarte'is SJ 
The core authors group is recognized as those authors with more publications and influence than others. On the basis of Price Law [46] (for the equation, see Multimedia Appendix 4), the minimum output of core author is obtained, namely, approximately 3.35 (ie, $0.749 \times 20^{1 / 2}$ ), which means that the publication output of every core author is not less than 4 . From this research, we can identify 266 core authors who have collectively published 1435 papers or $53.07 \%$ (1435/2704) of the total number of publications.

\section{Institution and Collaboration}

Statistical data analysis shows that the 2704 identified publications in the mHealth field were distributed among 3040 institutions. As shown in Table 3, authors from top 10 research institutions have published $449(16.61 \%, 449 / 2704)$ papers. The University of Michigan performed well, being seen as the most productive institution in mHealth research, followed by The University of Washington and Harvard University. All 10 institutions are universities, with 9 being based in the United States. The TLCS and TGCS of the University of Washington can be seen as the highest among the universities. Harvard University has the highest AGCS, with high academic influence and collaboration in mHealth research, followed by the University of Washington.

Compared with other forms of collaboration, institutional collaboration provides a measure to examine the interactions between institutions on a more granular level [47]. After being pruned [48], the major collaboration relationship of institutions related to mHealth research is shown in Figure 5, in which the institution labeling is shown based on the citation frequencies with 20 threshold levels (for list of the corresponding relations between the abbreviations and the full forms of the main institutions, see Multimedia Appendix 5). It is noted that there are 5 universities that present higher centrality with the purple circle, namely: The University of Michigan, University of California San Francisco, Stanford University, University of Pittsburgh, and The University of Pennsylvania, which demonstrated the central position and academic importance in the collaborative network of mHealth research. The links between institutions are relatively few, which coincides with the foregoing analysis.

\section{Country and Collaboration}

In total, scholars from 111 countries and territories have contributed to research on mHealth. A total of 10 countries and territories have contributed to the publication of 2477 papers (shown in Table 4). The United States, which is the most productive country in mHealth research, ranks the first in publication outputs, accounting for $46.97 \%$ (1270/2704) of the total. The United Kingdom, Australia, Canada, and China are not far behind. Moreover, when combining with the report released by the World Bank [49], it can be acknowledged that there are 20 lower middle-income countries (LMICs) that have contributed to mHealth research. A total of $197(7.29 \%$, 197/2704) papers were contributed to by authors in LMICs.

Furthermore, the TLCS and TGCS of the United States are the highest, followed by the United Kingdom and Canada. The top 6 countries in a descending order by AGCS, which indicates the high average quality of these papers, are the United States, Canada, the United Kingdom, China, Australia, and Germany.

Figure 6 shows the collaboration relationship of the most productive countries and territories. Country and territory labeling is shown based on the citation frequencies with 10 threshold levels (for list of the corresponding relations between the abbreviations and the full forms of the main countries and territories, see Multimedia Appendix 6). The United States is obviously the most active country in mHealth research worldwide. In the mHealth field, the United States plays an irreplaceable leading role, although the collaboration of authors inside the country is relatively scarce. It is also noteworthy that there are another 4 countries and territories that demonstrate higher centrality with the purple circle, namely, England, Australia, South Korea, and China. 
Table 3. Top 10 institutions on mobile health (mHealth) research.

\begin{tabular}{|c|c|c|c|c|c|c|c|}
\hline No. & Institution & $\operatorname{Recs}^{\mathrm{a}}$ & Publication, $\%$ & Cumulative percentage & TLCS $^{\mathrm{b}}$ & TGCS $^{\mathrm{c}}$ & $\operatorname{AGCS}^{\mathrm{d}}$ \\
\hline 1 & University of Michigan & 60 & 2.22 & 2.22 & 101 & 462 & 7.70 \\
\hline 2 & University of Washington & 56 & 2.07 & 4.29 & 176 & 818 & 14.61 \\
\hline 3 & Harvard University & 53 & 1.96 & 6.25 & 91 & 775 & 14.62 \\
\hline 4 & University of California, San Francisco & 48 & 1.78 & 8.03 & 56 & 401 & 8.35 \\
\hline 5 & Columbia University & 44 & 1.63 & 9.65 & 66 & 275 & 6.25 \\
\hline 6 & University of Sydney & 40 & 1.48 & 11.13 & 42 & 339 & 8.48 \\
\hline 7 & Johns Hopkins Bloomberg School of Public Health & 39 & 1.44 & 12.57 & 46 & 220 & 5.64 \\
\hline 8 & University of California, Los Angeles & 39 & 1.44 & 14.02 & 83 & 540 & 13.85 \\
\hline 9 & Johns Hopkins University & 35 & 1.29 & 15.31 & 22 & 137 & 3.91 \\
\hline 10 & University of Pittsburgh & 35 & 1.29 & 16.60 & 84 & 334 & 9.54 \\
\hline
\end{tabular}

${ }^{\mathrm{a}}$ Recs: number of published papers.

${ }^{b}$ TLCS: total local citation score.

${ }^{\mathrm{c}}$ TGCS: the total global citation score.

dAGCS: average global citation score.

Figure 5. The collaboration relationship between institutions related to mHealth research.

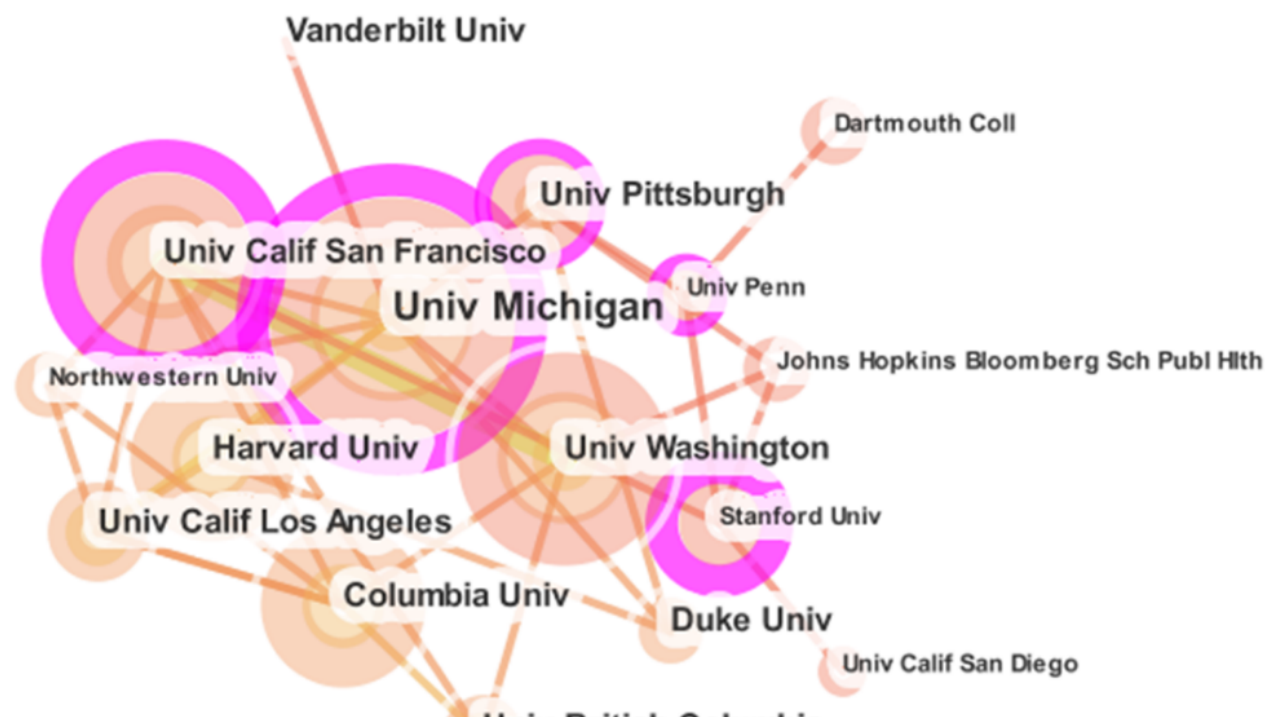

Univ British Columbia 
Table 4. Top 10 countries and territories.

\begin{tabular}{|c|c|c|c|c|c|}
\hline Country and territory & $\operatorname{Recs}^{\mathrm{a}}$ & $\mathrm{TLCS}^{\mathrm{b}}$ & TGCS $^{\mathrm{c}}$ & $\operatorname{ALCS}^{\mathrm{d}}$ & $\mathrm{AGCS}^{\mathrm{e}}$ \\
\hline United States & 1254 & 1721 & 11648 & 1.37 & 9.30 \\
\hline United Kingdom & 263 & 171 & 2141 & 0.65 & 8.14 \\
\hline Australia & 178 & 150 & 1371 & 0.84 & 7.70 \\
\hline Canada & 175 & 243 & 1583 & 1.39 & 9.05 \\
\hline People's Republic of China & 136 & 98 & 1061 & 0.72 & 7.80 \\
\hline South Korea & 116 & 62 & 577 & 0.53 & 4.97 \\
\hline Spain & 106 & 39 & 573 & 0.37 & 5.41 \\
\hline Taiwan & 88 & 94 & 818 & 1.07 & 9.30 \\
\hline Germany & 83 & 27 & 499 & 0.33 & 6.01 \\
\hline Netherlands & 78 & 36 & 442 & 0.46 & 5.67 \\
\hline
\end{tabular}

${ }^{\mathrm{a}}$ Recs: number of published papers.

${ }^{\mathrm{b}}$ TLCS: total local citation score.

${ }^{\mathrm{c}}$ TGCS: the total global citation score.

${ }^{\mathrm{d}}$ ALCS: average local citation score.

${ }^{\mathrm{e}}$ AGCS: average global citation score.

\section{Research Hotspots}

\section{Temporal Bar Graph for High-Frequency and High-Burst Keywords}

There are 71 keywords with a burst strength more than 1 and frequency not less than 10, which were ranked according to the frequency of keyword (for the details, see Multimedia Appendix 7). Each of these keywords holds the intervals of date in which the bursts occurred. All 71 keywords cover the research frontier of mHealth to a great extent. In addition, the frequencies of these keywords are 2028 times, showing that $1.28 \%$ (71/5543) of keywords accounted for $16.46 \%(2028 / 12,318)$ of the total 12,318 frequencies.
The temporal bar graph for the 27 burst terms clearly represents an evolution in topics over time, demonstrating the updating and interacting of the literature. In Figure 7, we can see that mobile telemedicine, mHealth units, and PDA were run through the research on mHealth in the period between 2000 and 2012, suggesting that the application of mobile technologies in health care has begun to receive greater attention. This phenomenon corresponds to the widespread application of information technology in every walk of life in the early 21 st century. In this body of knowledge, we can identify some main devices that have been applied to the health care field during the period of 2005 to 2010, including Bluetooth, body sensor networks, and mobile computing. 
Figure 6. The collaboration relationship of country and territory related to mHealth research.

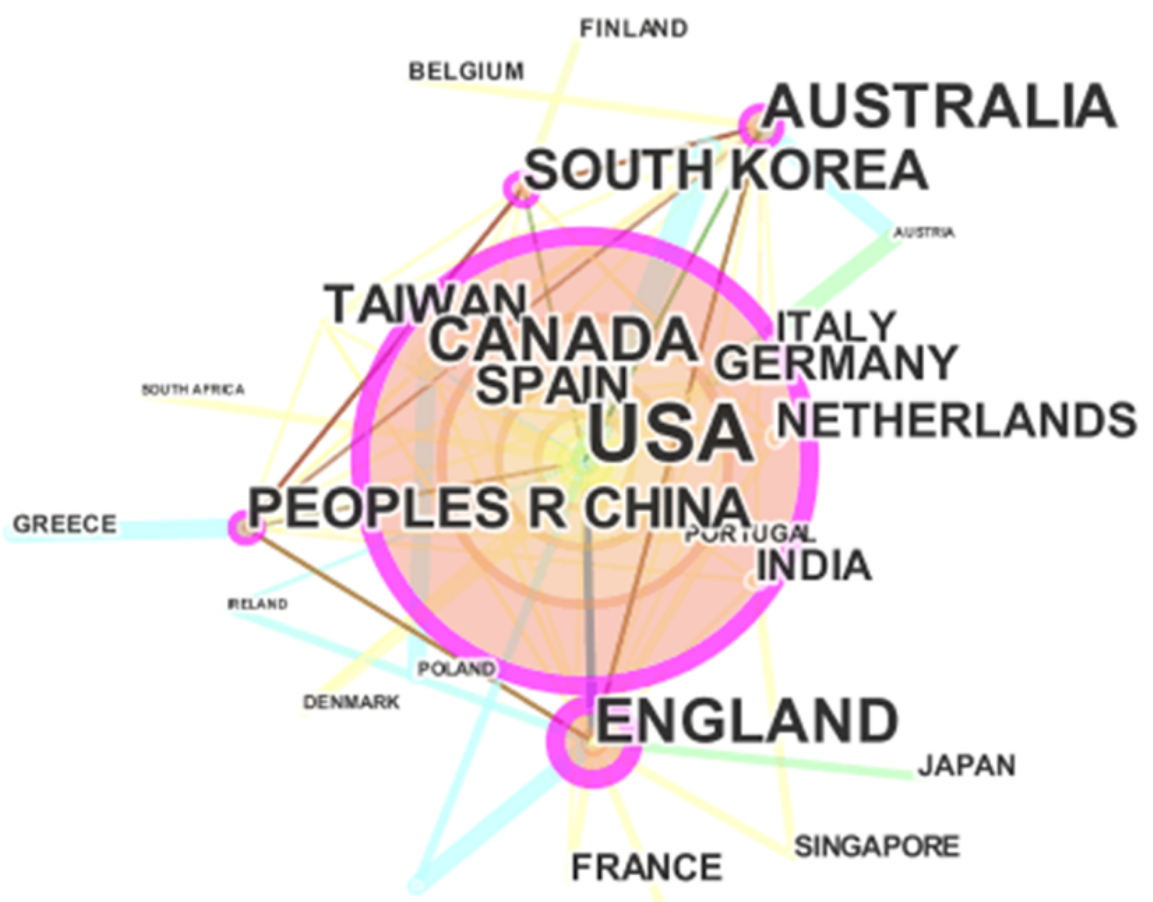

SWEDEN

Figure 7. Temporal bar graph for burst terms. ECG: electrocardiogram; PDA: personal digital assistant; TAM: technology acceptance model.

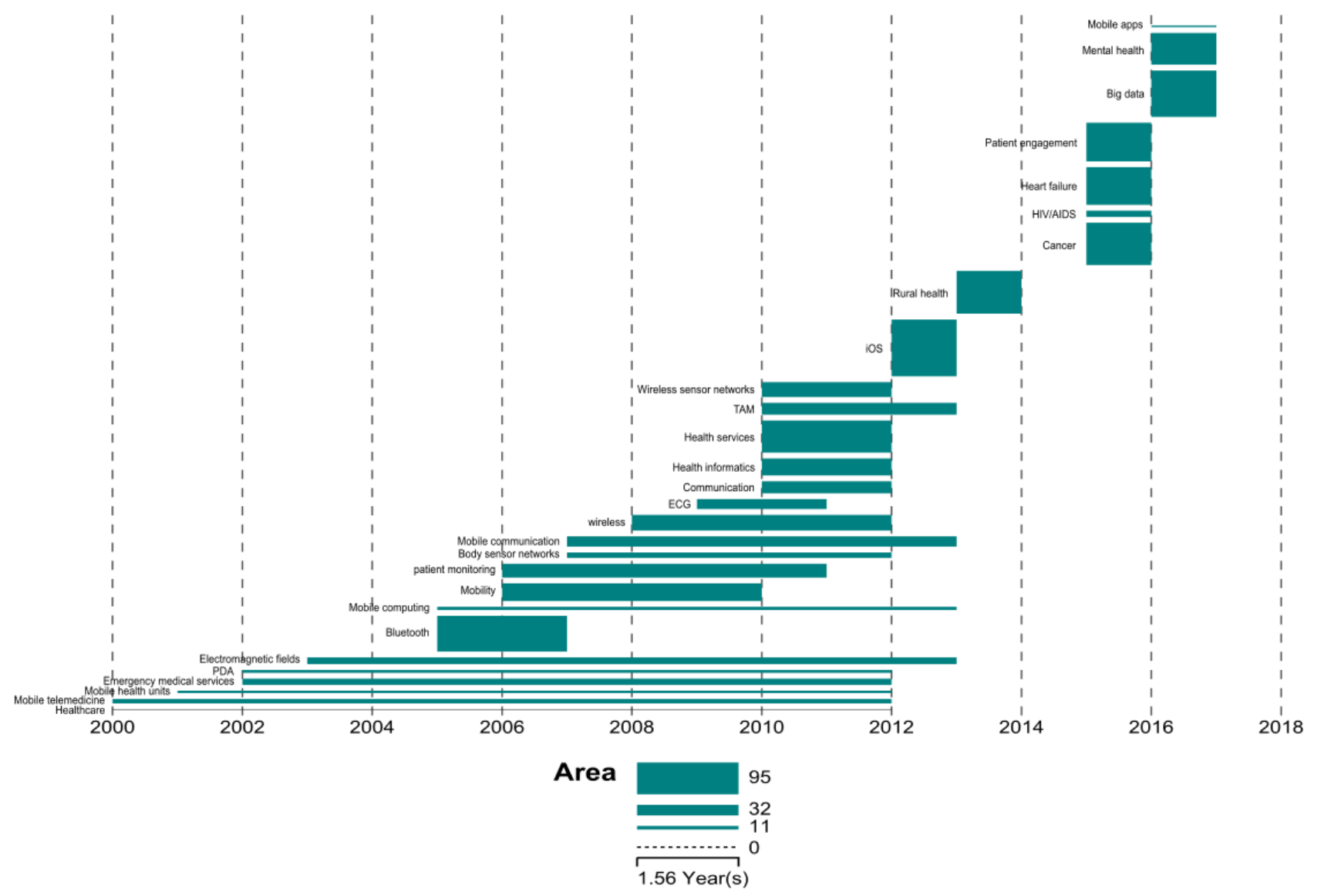

From 2010 to 2014 , the major burst terms were technology acceptance model (TAM), iOS, health services, and rural health.
It showed that the research focus had turned to the integration of health technology with health services, and that researchers 
had begun to explore how to improve technological acceptation from users. The representative burst terms from 2015 to 2016 were patient engagement, mental health, illness, and big data, suggesting that patient engagement and smart prevention methods have been a major research focus in the current new technology environment in the recent years.

\section{Research Topic Distribution}

The 71 keywords identified in the mHealth field were divided into 12 clusters through hierarchical cluster analysis, indicating the topics are broad and varied. The cluster name of each cluster was refined, based on the keywords in the respective cluster, all of which are presented in Table 5. That is, Cluster 1 refers to security and privacy; Cluster 2 focuses on health monitoring and $\mathrm{u}$-health; Cluster 3 is associated to health care and mobile computing; Cluster 4 is related to body sensor networks and patient monitoring; Cluster 5 refers to cell phones and health surveillance; Cluster 6 is about text messaging and health intervention; Cluster 7 focuses on social support, social media, and health promotion; Cluster 8 is related to mobile apps and mental health; Cluster 9 refers to mobile technology, nursing, and data mining; Cluster 10 is associated to self-care and patient engagement; Cluster 11 focuses on health services and health education; and Cluster 12 is related to TAM, chronic disease, and home health monitoring.

\section{Social Network Analysis}

On the basis of the $71 \times 71$ similarity matrix, it was possible to calculate the density of the network, which is 0.007 , a relatively low level. To explicitly demonstrate the networking relationship and obtain more powerful and intuitive results, we formed the $52 \times 52$ co-occurrence matrix based on the original $71 \times 71$ co-occurrence matrix, of which the keyword that correspond to any row or any column has not less than 12 frequencies. On the basis of the new matrix, a network was generated using Netdraw2.0 embedded in Ucinet6.6 (shown in Figure 8), which intuitively reflects the relationships among the high-frequency and highly bursting keywords.

The graph shown in Figure 8 semantically interrelates and chronologically links diverse fields of mHealth research. A total of 4 major areas can be identified: (1) the top left subnetwork is related to patient engagement and patient intervention research, which mostly covers Clusters $5-7$; (2) the top right topics deal with health monitoring and self-care research, which roughly include Cluster 2, Cluster 8, Cluster 10, and Cluster 12; (3) the bottom right is linked to mobile device and mobile computing research, which mainly contains Clusters 3-4 and Cluster 9; and (4) the bottom left relates to security and privacy studies, which includes Cluster 1.

Table 5. Twelve clusters of mobile health (mHealth) research.

\begin{tabular}{|c|c|c|c|}
\hline Cluster & Number of keywords & Cluster name & Keywords \\
\hline 1 & 2 & Security and privacy & Security; privacy \\
\hline 2 & 8 & Health monitoring and u-health & $\begin{array}{l}\mathrm{ECG}^{\mathrm{a}} \text {; cloud computing; wireless body area networks; health } \\
\text { monitoring; big data; mobile telemedicine; u-health; wireless }\end{array}$ \\
\hline 3 & 4 & Health care and mobile computing & $\begin{array}{l}\text { Health care; mobile computing; Internet of things; ubiquitous } \\
\text { computing }\end{array}$ \\
\hline 4 & 4 & Body sensor networks and patient monitoring & $\begin{array}{l}\text { Body sensor networks; wireless sensor networks; decision } \\
\text { support system; patient monitoring; mobility; Bluetooth }\end{array}$ \\
\hline 5 & 6 & Cell phones and health surveillance & $\begin{array}{l}\text { Cell phones; health; surveillance; epidemiology; informatics } \\
\text { electromagnetic fields; maternal health }\end{array}$ \\
\hline 6 & 7 & Text messaging and health intervention & $\begin{array}{l}\text { Text messaging; HIV/AIDS; randomized controlled trial; } \\
\text { cancer; overweight; nutrition; intervention study }\end{array}$ \\
\hline 7 & 7 & Social support, social media and health promotion & $\begin{array}{l}\text { Internet; intervention; social support; social media; health } \\
\text { promotion; communication; public health }\end{array}$ \\
\hline 8 & 4 & Mobile apps and mental health & $\begin{array}{l}\text { Mobile apps; ecological momentary assessment; mental health } \\
\text { bipolar disorder }\end{array}$ \\
\hline 9 & 7 & Mobile technology, nursing, and data mining & $\begin{array}{l}\text { Mobile technology; PDA }{ }^{\mathrm{b}} \text {; health informatics; Android; data } \\
\text { mining; nursing; iOS }\end{array}$ \\
\hline 10 & 4 & Self-care and patient engagement & Self-care; patient engagement; heart failure; quality of life \\
\hline 11 & 4 & Health services and health education & $\begin{array}{l}\text { Information technology; health services; emergency medical } \\
\text { services; health education }\end{array}$ \\
\hline 12 & 11 & $\mathrm{TAM}^{\mathrm{c}}$, chronic disease, and home health monitoring & $\begin{array}{l}\text { Mobile health units; cardiovascular disease; TAM; rural health } \\
\text { home health monitoring; older adults; hypertension; mobile } \\
\text { learning; screening; implementation; mobile communication }\end{array}$ \\
\hline
\end{tabular}

${ }^{a}$ ECG: electrocardiogram.

bPDA: personal digital assistant.

${ }^{\mathrm{C}}$ TAM: technology acceptance model. 
Figure 8. Social network map of the original $52 \times 52$ co-occurrence matrix. ECG: electrocardiogram; PDA: personal digital assistant; TAM: technology acceptance model.

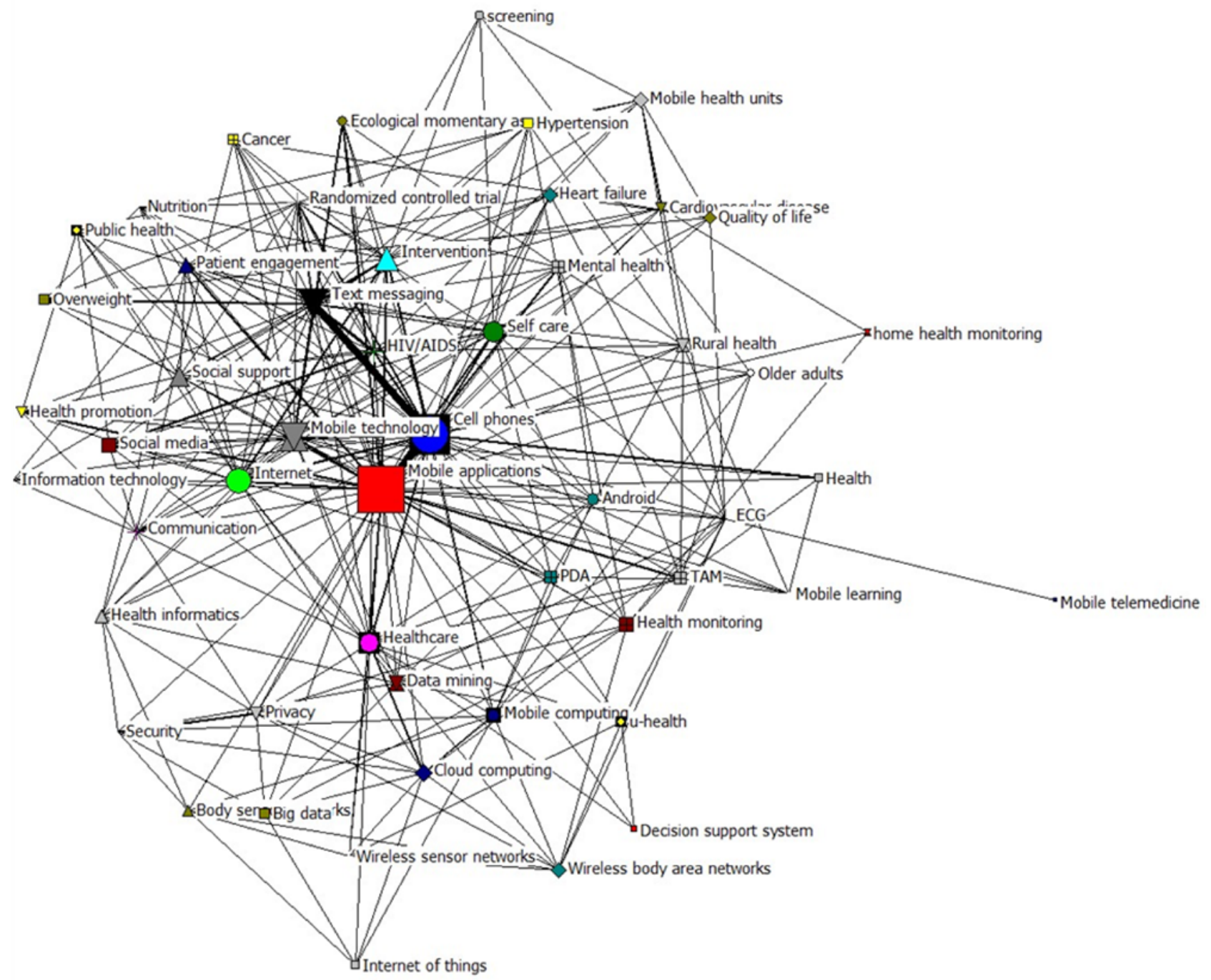

\section{Discussion}

\section{Principal Findings}

This study has demonstrated that the growth of literature related to mHealth research has accelerated in recent years, and that the influence is continually increasing. As we know, with the emergence of mobile phone technologies from 2006 to 2010 , the field of mHealth entered a phase of rapid innovation and, in parallel, unfettered proliferation. In addition, mHealth Alliance, founded in 2008, has played an important role in advancing the field of mHealth through thought leadership and by convening a range of stakeholders, which focuses on advancing mHealth technology in global health care through policy research, advocacy, and outreach [50]. Obviously, all of these events present a large research scope on mHealth, and the number of publications started to increase dramatically during the period from 2009 to 2016, although it was less before 2008 . In addition, based on the logical growth curve equation of mHealth literature, combined with the fact that some important papers published before December 28, 2016, are not indexed in WoSCC, it is reasonable to infer that mHealth literature published in 2017 is expected to reach more than 1000, and that the average annual growth rate of literature on mHealth will reach nearly $60 \%$ (648/410-1) after 2016.

Additionally, IF is seen to be a metric of excellence for journals, that is, journals with higher IF are often deemed to be more important than those with lower IF. In the past 2 years, there is an increase of IF for major journals related to mHealth, which further reflects the concern of researchers to mHealth.

Our study showed that the degree of author collaboration is relatively high, that the core author group is fundamentally formed, and that collaboration between the core authors should be further strengthened. Scientific collaboration has become prevalent in various disciplines [51]. In this study, the total degree of author collaboration was more than 4 during the past 2 decades and, compared with other disciplines, the collaboration degree of international mHealth stays above the average level in scientific collaboration [52]. As we understand, with the development of science and the explosion of knowledge, nobody is an expert in everything [53]. It is an arduous task for an individual to fully understand the extensive knowledge of various fields in the information era. Research on mHealth is no exception and this requires more experts from different field to collaborate together to answer important 
questions. Additionally, collaboration can facilitate the sharing and dissemination of knowledge and attract more attention to the field $[54,55]$.

Obviously, some specific authors played very important roles and had a big impact in the mHealth field and on future development, representing "core strength" in this field. The output of core authors in the mHealth field represents approximately $50 \%(1435 / 2704)$ of the total number of publications. According to the Law of Price, we can find that the core authors group has fundamentally been formed and that the publication output of the core authors will increase over time. However, there are only 4 major clusters of authors, which can be regarded as the backbone in the field, indicating that the current collaboration of core authors is not tight and stable. Moreover, when combined with the analysis above, it can be concluded that the core researchers in the mHealth field should further strengthen their collaboration to form a more stable and core collaborative group.

In our study, it can be seen that the leading research power is in the United States and that the collaborative relationship of institutions or countries is not relatively tight. Although 3040 institutions have been involved in research on mHealth, indicating a remarkable concern, publication output on mHealth research is distributed unevenly between institutions. Links between institutions are relatively few, according to the collaborative relationship map, which means less collaboration among institutions and less willingness to collaborate, except for the network consisting of numerous American colleges and universities. Additionally, it can be inferred that universities are major research forces, similar to other research fields. Institution collaboration, in general, should be further strengthened in future. Moreover, combining the sparse institution collaboration, it can be further inferred that the collaboration mainly occurs among authors with different academic professional backgrounds from the same institution.

Furthermore, the major industrialized countries (such as G7 countries: the United States, the United Kingdom, Germany, Canada, Italy, France, and Japan) are mostly in the core of the country collaboration network, suggesting that economic development and scientific investment have much contribution to the publication outputs in mHealth. However, China, which is representative of the developing countries, also pays more attention to public health and plays a prior role in the mHealth studies. Additionally, based on the country collaboration graph, it can be inferred that institutions located in the United States are more inclined to collaborate with domestic institutions, suggesting institutions in the United States have a relatively low tendency toward international collaboration. In fact, scientific collaboration relationships are highly resource-dependent [56] and internationalization of science, to a certain degree, depends on the attractiveness of a partner in the global network. Therefore, the international collaboration for institutions in mHealth research encounters challenges as well, particularly for developing countries that are confronted with critical internal conditions (eg, policy and funds) that often prevent them from collaborating with high scientific capacity. To change this situation, measures should be taken which will benefit the developing country itself from the application of
mHealth in the near future. For example, more scholars related to mHealth research from the developing country should be supported by related countries or institutions to study and communicate in the United States, or some advanced experts could be invited to guide the research in the developing country.

In this study, we find that modern ICT is increasingly being integrated with health care systems, and that research topic burst on mHealth is relatively decentralized. The 71 identified keywords demonstrate the research frontier of mHealth field to a very great extent. From the temporal bar graph, it can be seen that research focus has already begun to shift from acceptance and feasibility to outcome of mHealth to some extent and that patient engagement through social media and mobile computing has started receiving more attention in recent years. Generally, mHealth has been seen to be a new effective approach to increasing means and efficiency of care delivery in the health domain using ICT. Additionally, mHealth would provide support for medical service decisions by means of second development and utilization of medical and health care data, such as mobile computing and data mining.

The hierarchical cluster analysis intuitively displays the 12 keyword clusters and the relationship between topics, each of which represents a research direction on mHealth. Compared with other studies, mHealth research topics are relatively decentralized at present, and social network analysis presents the 4 major areas, each of which covers 1 or several of 12 clusters. In addition, the top left subnetwork receives more attention than others. Generally, research on mHealth should be further strengthened in these 4 areas, and the research topics would also need to be further focused in future, which will be beneficial to health care services.

\section{Limitations}

Although findings are based on the above analysis, there are still several potential limitations that may encourage further research efforts. First, this study only focuses on literature indexed by WoSCC. Although WoSCC emphases paper quality to ensure accurate and meaningful data, it leads to some papers related to mHealth not being covered. Moreover, there are several high-quality papers that are still not indexed by WoSCC due to time-lag, especially those published at the end of 2016. All of these will have some impact on the accuracy of research output on mHealth.

Second, there might be some biases of understanding for author collaboration because some different authors with the same name or abbreviation exist, who are affiliated to different institutions. In addition, some authors are simply "token co-authors" included in some papers. Therefore, the result of author relationship analysis for mHealth research would be influenced by the accuracy of the indexing author.

Finally, although temporal analysis and hierarchy cluster analysis are quite useful methods for exploring topic evolution and identifying hotspots in 1 field, the results may be affected by the accuracy of keywords. We used 3 main methods of cleaning keywords in this research, but there still exists some keywords with the same meaning, which will affect the cluster results to some extent. 


\section{Conclusions}

In this study, a comprehensive bibliometric analysis on mHealth research was conducted, with the data source being the WoSCC, using various tools. Different visualization methods were used to interactively explore and understand the specific datasets. On the basis of the above results and discussion, some valuable results for mHealth research were obtained, including information on collaboration characteristics and research topic bursts. Meanwhile, with the deep contingency of mobile technologies and health care services, it is reasonable to believe that the literature related to mHealth research will grow at an exponential rate in future and that the collaboration of core authors will strengthen after core author groups officially form. In addition, although the United States has the leading research power in mHealth area, the collaborative relationship of institutions or countries should be reinforced to promote the global mHealth field. In general, the focus of research topics on mHealth should be enhanced in the future.

It should be noted that mHealth has begun to be an important part of digital health, which is the convergence of digital and genomic technologies with health, health care, living, and society to enhance the efficiency of health care delivery and make medicines more personalized and precise [57]. The broad scope of digital health includes categories such as mHealth, health information technology, wearable devices, telehealth and telemedicine, and personalized medicine [58-60]. All of these are helpful to promote the emergence and development of quality research and provide a potential guideline for scientific researchers when launching new projects in the future.

\section{Acknowledgments}

This study was supported by the Fundamental Research Funds for the Central Universities, HUST (No. 2017WKYXQY005). The authors would like to thank all anonymous reviewers for their valuable comments and input to this research.

\section{Authors' Contributions}

LS, the first author, designed and conducted the study into literature distribution and topic bursts in the mHealth field. BX, the second author, contributed to the research into collaboration characteristics. All other authors contributed to the manuscript's preparation and approved the final accepted version.

\section{Conflicts of Interest}

None declared.

\section{Multimedia Appendix 1}

Detailed search strategy of WoSCC.

[PDF File (Adobe PDF File), 38KB-Multimedia Appendix 1]

\section{Multimedia Appendix 2}

List of papers published as top 7 most productive first authors.

[PDF File (Adobe PDF File), 126KB-Multimedia Appendix 2]

\section{Multimedia Appendix 3}

List of relevant information for main authors of the 4 clusters in collaboration relationship map of productive authors.

[PDF File (Adobe PDF File), 56KB-Multimedia Appendix 3]

\section{Multimedia Appendix 4}

The equation for the minimum output of core author.

[PDF File (Adobe PDF File), 13KB-Multimedia Appendix 4]

\section{Multimedia Appendix 5}

List of the corresponding relations between the abbreviations and the full forms of the main institutions.

[PDF File (Adobe PDF File), 46KB-Multimedia Appendix 5]

\section{Multimedia Appendix 6}

List of the corresponding relations between the abbreviations and the full forms of the main countries and territories.

\section{[PDF File (Adobe PDF File), 46KB-Multimedia Appendix 6]}




\section{Multimedia Appendix 7}

List of keywords with burst strength more than 1 and frequency not less than 10 .

[PDF File (Adobe PDF File), 125KB-Multimedia Appendix 7]

\section{References}

1. Labrique AB, Vasudevan L, Kochi E, Fabricant R, Mehl G. mHealth innovations as health system strengthening tools: 12 common applications and a visual framework. Glob Health Sci Pract 2013 Aug;1(2):160-171 [FREE Full text] [doi: 10.9745/GHSP-D-13-00031] [Medline: 25276529]

2. Mehl G, Labrique AB. Prioritizing integrated mHealth strategies for universal health coverage. Science 2014 Sep 12;345(6202):1284-1287. [doi: 10.1126/science.1258926] [Medline: 25214614]

3. Agarwal S, Perry HB, Long LA, Labrique AB. Evidence on feasibility and effective use of mHealth strategies by frontline health workers in developing countries: systematic review. Trop Med Int Health 2015 Aug;20(8):1003-1014. [doi: 10.1111/tmi.12525] [Medline: 25881735]

4. de la Vega R, Miró J. mHealth: a strategic field without a solid scientific soul. a systematic review of pain-related apps. PLoS One 2014 Jul;9(7):e101312. [doi: 10.1371/journal.pone.0101312] [Medline: 24999983]

5. Liu C, Zhu Q, Holroyd KA, Seng EK. Status and trends of mobile-health applications for iOS devices: a developer's perspective. J Syst Softw 2011 Nov;84(11):2022-2033 [FREE Full text] [doi: 10.1016/j.jss.2011.06.049]

6. Laxminarayan S, Istepanian RS. Unwired e-med: the next generation of wireless and internet telemedicine systems. IEEE Trans Inf Technol Biomed 2000 Sep;4(3):189-193. [doi: 10.1109/TITB.2000.5956074] [Medline: 11026588]

7. World Health Organisation. Geneva: WHO Press; 2011. mHealth: new horizons for health through mobile technologies (Global Observatory for eHealth) URL: http://apps.who.int/iris/bitstream/handle/10665/44607/9789241564250 eng. pdf;jsessionid=B5BF42C05D0775CCD552FD82AA82543A?sequence=1 [accessed 2017-05-24] [WebCite Cache ID 6vKke0R1z]

8. Akter S, Ray P. mHealth - an ultimate platform to serve the unserved. Yearb Med Inform 2010 Aug;19(1):94-100 [FREE Full text] [doi: 10.1055/s-0038-1638697] [Medline: 20938579]

9. BinDhim NF, Hawkey A, Trevena L. A systematic review of quality assessment methods for smartphone health apps. Telemed J E Health 2015 Feb;21(2):97-104 [FREE Full text] [doi: 10.1089/tmj.2014.0088] [Medline: 25469795]

10. Martínez-Pérez B, de la Torre-Díez I, López-Coronado M. Mobile health applications for the most prevalent conditions by the World Health Organization: review and analysis. J Med Internet Res 2013 Jun 14;15(6):e120 [FREE Full text] [doi: 10.2196/jmir.2600] [Medline: 23770578]

11. Mosadeghi-Nik M, Askari MS, Fatehi F. Mobile health (mHealth) for headache disorders: a review of the evidence base. J Telemed Telecare 2016 Dec;22(8):472-477. [doi: 10.1177/1357633X16673275] [Medline: 27799450]

12. de la Torre Díez I, Garcia-Zapirain B, Méndez-Zorrilla A, López-Coronado M. Monitoring and follow-up of chronic heart failure: a literature review of eHealth applications and systems. J Med Syst 2016 Jul;40(7):179. [doi:

10.1007/s10916-016-0537-y] [Medline: 27286984]

13. Catalani C, Philbrick W, Fraser H, Mechael P, Israelski DM. mHealth for HIV treatment \& prevention: a systematic review of the literature. Open AIDS J 2013 Aug 13;7:17-41 [FREE Full text] [doi: 10.2174/1874613620130812003] [Medline: 24133558]

14. Arambepola C, Ricci-Cabello I, Manikavasagam P, Roberts N, French DP, Farmer A. The impact of automated brief messages promoting lifestyle changes delivered via mobile devices to people with type 2 diabetes: a systematic literature review and meta-analysis of controlled trials. J Med Internet Res 2016 Apr 19;18(4):e86 [FREE Full text] [doi: 10.2196/jmir.5425] [Medline: 27095386]

15. Hall AK, Cole-Lewis H, Bernhardt JM. Mobile text messaging for health: a systematic review of reviews. Annu Rev Public Health 2015 Mar 18;36:393-415 [FREE Full text] [doi: 10.1146/annurev-publhealth-031914-122855] [Medline: 25785892]

16. Berrouiguet S, Baca-García E, Brandt S, Walter M, Courtet P. Fundamentals for future mobile-Health (mHealth): a systematic review of mobile phone and Web-based text messaging in mental health. J Med Internet Res 2016 Jun 10;18(6):e135 [FREE Full text] [doi: 10.2196/jmir.5066] [Medline: 27287668]

17. Free C, Phillips G, Watson L, Galli L, Felix L, Edwards P, et al. The effectiveness of mobile-health technologies to improve health care service delivery processes: a systematic review and meta-analysis. PLoS Med 2013 Jan;10(1):e1001363 [FREE Full text] [doi: 10.1371/journal.pmed.1001363] [Medline: 23458994]

18. Thilarajah S, Clark RA, Williams G. Wearable sensors and mobile health (mHealth) technologies to assess and promote physical activity in stroke: a narrative review. Brain Impair 2016 Feb 15;17(1):34-42 [FREE Full text] [doi:

10.1017/BrImp.2016.1]

19. Källander K, Tibenderana JK, Akpogheneta OJ, Strachan DL, Hill Z, ten Asbroek AH, et al. Mobile health (mHealth) approaches and lessons for increased performance and retention of community health workers in low- and middle-income countries: a review. J Med Internet Res 2013 Jan 25;15(1):e17 [FREE Full text] [doi: 10.2196/jmir.2130] [Medline: $\underline{23353680]}$

20. Pritchard A. Statistical bibliography or bibliometrics? J Doc 1969 Jan;25(4):348-349 [FREE Full text] 
21. Pendlebury DA. Mendeley. 2008. Using bibliometrics in evaluating research URL: https://www.mendeley.com/ research-papers/using-bibliometrics-evaluating-research/ [accessed 2018-03-19] [WebCite Cache ID 6y1se4KUY]

22. Van Leeuwen T, Visser M, Moed H, Nederhof T, Van Raan A. The Holy Grail of science policy: exploring and combining bibliometric tools in search of scientific excellence. Scientometrics 2003 Jun;57(2):257-280. [doi: 10.1023/A:1024141819302]

23. Dong D, Chen M. Publication trends and co-citation mapping of translation studies between 2000 and 2015 . Scientometrics 2015 Oct 8;105(2):1111-1128. [doi: 10.1007/s11192-015-1769-1]

24. Orpin PG, Bainbridge TA, Botterill W. What can we learn from 20 years of fertility benchmarking in practice? Cattle Pract 2015 Oct;23:338-344 [FREE Full text]

25. Gomes LP, Esteves RV. Analysis of the management system of the healthcare waste in municipalities of Rio dos Sinos hydrographic basin. Eng Sanita Ambient 2012 Dec;17(4):377-384 [FREE Full text] [doi: 10.1590/S1413-41522012000400004]

26. Shen L, Xiong B, Hu J. Research status, hotspots and trends for information behavior in China using bibliometric and co-word analysis. J Doc 2017 Jul 10;73(4):618-633. [doi: 10.1108/JD-10-2016-0125]

27. Garfield E. Citation indexing for studying science. Nature 1970 Aug 15;227(5259):669-671. [doi: 10.1038/227669a0] [Medline: $\underline{4914589]}$

28. Cui L, Liu W, Yan L. Development of a text mining system based on the co-occurrence of bibliographic items in literature databases. New Tech of Libr and Inform Serv 2008 Aug;24(8):70-75.

29. Garfield E, Pudovkin AI, Istomin VS. Why do we need algorithmic historiography? J Am Soc Inf Sci Tec 2003 Mar;54(5):400-412. [doi: 10.1002/asi.10226]

30. Thulasi K, Arunachalam S. Mapping of cholera research in India using HistCite. Ann Libr Inform Stud 2010 Sep;57(3):310-326 [FREE Full text]

31. Lucio-Arias D. A validation study of HistCite (TM): Using the discoveries of fullerenes and nanotubes. In: Proceedings of ISSI: 11th international conference of the International Society for Scientometrics and Informetrics (Vols. I and II). 2007 Presented at: 11th International Conference of the International Society for Scientometrics and Informetrics; June 25-27; Madrid, Spain p. 886-887 URL: http://garfield.library.upenn.edu/papers/histcite2006.pdf

32. Han P, Shi J, Li X, Wang D, Shen S, Su X. International collaboration in LIS: global trends and networks at the country and institution level. Scientometrics 2013 Oct 18;98(1):53-72. [doi: 10.1007/s11192-013-1146-x]

33. Ren S, Wang Y, Ren X. Bibliometric analysis of the core authors in "Chinese Hospital Management Journal". Chin J of Med Libr and Inform Sci 2008 Apr;17(4):72-75.

34. Chen C. CiteSpace II: detecting and visualizing emerging trends and transient patterns in scientific literature. J Am Soc Inf Sic Tec 2006 Feb 1;57(3):359-377. [doi: 10.1002/asi.20317]

35. Chen $\mathrm{C}$. The centrality of pivotal points in the evolution of scientific networks. In: Proceedings of the 10 th international conference on Intelligent user interfaces. 2005 Presented at: IUI '05; January 10-13, 2005; San Diego, CA, USA p. $98-105$. [doi: 10.1145/1040830.1040859]

36. Liu GY, Hu JM, Wang HL. A co-word analysis of digital library field in China. Scientometrics 2011 Dec 24;91(1):203-217 [FREE Full text] [doi: 10.1007/s11192-011-0586-4]

37. Kleinberg J. Bursty and hierarchical structure in streams. In: Proceedings of the Eighth ACM SIGKDD International Conference on Knowledge Discovery and Data Mining. 2002 Presented at: KDD '02; July 23-26, 2002; Edmonton, AB, Canada p. 91-101. [doi: $10.1145 / 775047.775061$ ]

38. Sci2 Team. 2009. Sci2 tool : a tool for science of science research and practice URL: https://sci2.cns.iu.edu/user/index.php [accessed 2017-05-27] [WebCite Cache ID 6vKq1XbM8]

39. Mane KK, Börner K. Mapping topics and topic bursts in PNAS. Proc Natl Acad Sci U S A 2004 Apr 6;101(Suppl 1):5287-5290 [FREE Full text] [doi: 10.1073/pnas.0307626100] [Medline: 14978278]

40. Eck NJ, Waltman L. How to normalize cooccurrence data? An analysis of some well-known similarity measures. J Am Soc Inf Sci Tec 2009 Aug;60(8):1635-1651 [FREE Full text] [doi: 10.1002/asi.21075]

41. Ding Y, Chowdhury GG, Foo S. Bibliometric cartography of information retrieval research by using co-word analysis. Inform Process Manag 2001 Nov;37(6):817-842 [FREE Full text] [doi: 10.1016/S0306-4573(00)00051-0]

42. Lee WH. How to identify emerging research fields using scientometrics: an example in the field of Information Security. Scientometrics 2008 Jul 12;76(3):503-525 [FREE Full text] [doi: 10.1007/s11192-007-1898-2]

43. Borgatti SP, Everett MG, Johnson JC. Analyzing Social Networks. 1st Edition. London: SAGE Publications Ltd; 2013.

44. Hu J, Zhang Y. Research patterns and trends of Recommendation System in China using co-word analysis. Inform Process Manag 2015 Jul;51(4):329-339 [FREE Full text] [doi: 10.1016/j.ipm.2015.02.002]

45. Wang C, Wang Z. Evaluation of the models for Bradford's law. Scientometrics 1998 May;42(1):89-95 [FREE Full text] [doi: $10.1007 / \mathrm{BF} 02465014]$

46. Wang W. Inforometrics and Its Medical Applications (2nd Edition/Undergraduate Health Management). Beijing: People's Health Publishing House; 2014.

47. Yan E, Sugimoto CR. Institutional interactions: exploring social, cognitive, and geographic relationships between institutions as demonstrated through citation networks. J Am Soc Inf Sci Tec 2011 May 5;62(8):1498-1514 [FREE Full text] [doi: $\underline{10.1002 / \text { asi.21556] }}$ 
48. Schvaneveldt RW. Pathfinder Associative Network: Studies in Knowledge Organization. Norwood, NJ: Ablex Publishing Corp; 1990.

49. World Bank. 2017. List of Global Economics - DataBank URL: http://databank.worldbank.org/data/download/site-content/ CLASS.xls [accessed 2018-02-22] [WebCite Cache ID 6xQtpznao]

50. Monegain B. Healthcare IT News. 2013 Dec 8. mHealth Alliance South Africa bound URL: http://www.healthcareitnews.com/ news/mhealth-alliance-south-africa-bound [accessed 2018-03-19] [WebCite Cache ID 6y1k8yJeG]

51. Glanzel W. Coauthorship patterns and trends in the sciences (1980-1998): a bibliometric study with implications for database indexing and search strategies. Libr Trends 2002 Jan;50(3):461-473 [FREE Full text]

52. Ardanuy J. Scientific collaboration in Library and Information Science viewed through the Web of Knowledge: the Spanish case. Scientometrics 2011 Nov 9;90(3):877-890 [FREE Full text] [doi: 10.1007/s11192-011-0552-1]

53. Franceschet M. Collaboration in computer science: a network science approach. J Am Soc Inf Sci Tec 2011 Jul 28;62(10):1992-2012 [FREE Full text] [doi: 10.1002/asi.21614]

54. Franceschet M, Costantini A. The effect of scholar collaboration on impact and quality of academic papers. J Informetr 2010 Oct;4(4):540-553 [FREE Full text] [doi: 10.1016/j.joi.2010.06.003]

55. Gazni A, Didegah F. Investigating different types of research collaboration and citation impact: a case study of Harvard University's publications. Scientometrics 2011 Jan 25;87(2):251-265 [FREE Full text] [doi: 10.1007/s11192-011-0343-8]

56. Pouris A, Ho YS. Research emphasis and collaboration in Africa. Scientometrics 2013 Oct 12;98(3):2169-2184. [doi: 10.1007/s11192-013-1156-8]

57. Bhavnani SP, Narula J, Sengupta PP. Mobile technology and the digitization of healthcare. Eur Heart J 2016 Feb 11;37(18):1428-1438 [FREE Full text] [doi: 10.1093/eurheartj/ehv770] [Medline: 26873093]

58. Food and Drug Administration. Digital health. 2016 Aug 30. URL: https://www.fda.gov/medicaldevices/digitalhealth/ [accessed 2018-03-19] [WebCite Cache ID 6y1kNOplW]

59. Montagni I, Cariou T, Feuillet T, Langlois E, Tzourio C. Exploring digital health use and opinions of university students: field survey study. JMIR Mhealth Uhealth 2018 Mar 15;6(3):e65 [FREE Full text] [doi: 10.2196/mhealth.9131] [Medline: 29549071]

60. Fotis T. Digital health and perioperative care. J Perioper Pract 2017 Jun;27(6):126-127. [doi: 10.1177/175045891702700601] [Medline: 29239200]

\author{
Abbreviations \\ AGCS: average global citation score \\ ALCS: average local citation score \\ BICOMS: Bibliographic Item Co-Occurrence Mining System \\ ECG: electrocardiogram \\ ICT: information and communication technologies \\ IF: impact factor \\ LMICs: lower middle-income countries \\ mHealth: mobile health \\ PDA: personal digital assistant \\ Sci2: Science of Science \\ SMS: short messaging service \\ TAM: technology acceptance model \\ TGCS: total global citation score \\ TLCS: total local citation score \\ WoSCC: Web of Science Core Collection
}

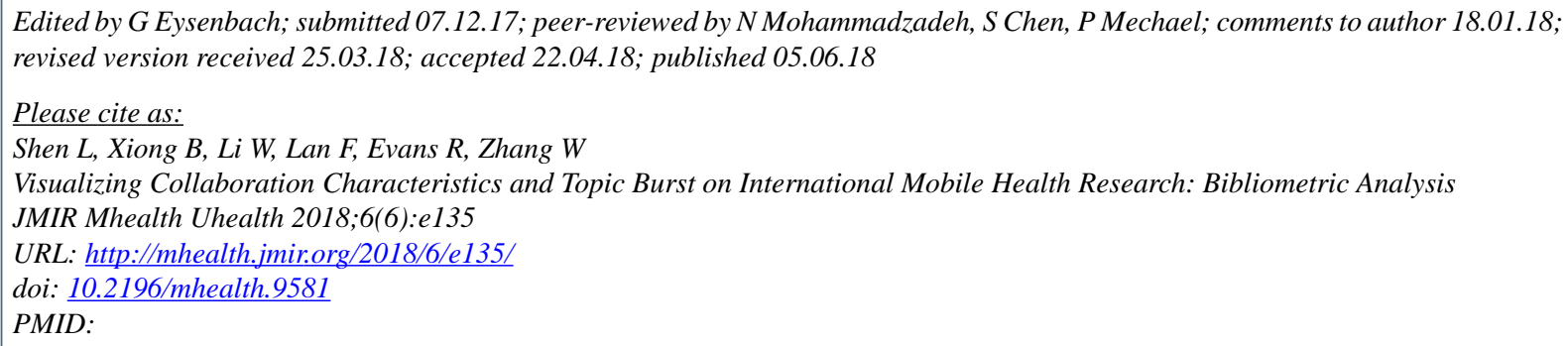


CLining Shen, Bing Xiong, Wei Li, Fuqiang Lan, Richard Evans, Wei Zhang. Originally published in JMIR Mhealth and Uhealth (http://mhealth.jmir.org), 05.06.2018. This is an open-access article distributed under the terms of the Creative Commons Attribution License (https://creativecommons.org/licenses/by/4.0/), which permits unrestricted use, distribution, and reproduction in any medium, provided the original work, first published in JMIR mhealth and uhealth, is properly cited. The complete bibliographic information, a link to the original publication on http://mhealth.jmir.org/, as well as this copyright and license information must be included. 